\title{
Characteristics of 1270 Chinese sibling pairs with cancer
}

\author{
Ju Liu ${ }^{1+}$, Jian Yin ${ }^{2,3+}$, Yiwei Liu' ${ }^{2,4}$, Zhijian Xu ${ }^{1}$ and Kai Zhang ${ }^{1 *}$
}

\begin{abstract}
Background: Previous research found that the cancer history of an individual's sibling may be a better indicator than that of the parents. We aim to provide recommendations for opportunistic screening for individuals whose sibling had been diagnosed with cancer.

Methods: During the physical examination in Cancer Hospital, Chinese Academy of Medical Sciences, 43,300 people were asked if they have at least two siblings who developed cancer.

Results: A total of 1270 sibling-pairs from 766 families developed cancer, including 367 pairs of brothers (Bro-pairs), 368 pairs of sisters (Sis-pairs), and 535 pairs of brother-and-sister (BroSis-pairs). The mean ages at diagnosis of cancer for the three groups were from 58 to 62 years. More than half of Bro-pairs (55.3\%) or Sis-pairs (51.1\%) had cancer from the same systemic origin, and more than a quarter of Bro-pairs (28.1\%) and Sis-pairs (37.2\%) developed the same type of cancer. However, only 36.0\% of BroSis-pairs developed cancers from the same systemic origin, and 18.9\% developed the same type of cancer. In Bro-pairs and BroSis-pairs, lung cancer and digestive system cancer were the most common cancers, while in Sis-pairs, breast cancer, lung cancer, cervical cancer, liver cancer and thyroid cancer were the most common ones.

Conclusions: If an individual's sibling is diagnosed with cancer, the individual should consider participating in opportunistic screening annually, especially for lung cancer and digestive system cancers for both sexes. For sisters, breast cancer, cervical cancer and thyroid cancer should be screened early. Additionally, genetic services are essential for individuals who have siblings with cancer.
\end{abstract}

Keywords: Cancer, Family history, Sibling, Screening, Malignant disease, Genetic service

\section{Introduction}

Cancer incidence and mortality are rapidly growing worldwide [1]. There is increasing attention to cancer prevention and early detection programs, especially among people with a family history of cancer. Family history is a strong indicator for evaluating cancer risks $[2,3]$, as people with a family history of cancer have a

\footnotetext{
* Correspondence: kai87968@sina.com

†Ju Liu and Jian Yin contributed equally to this work.

'Department of Cancer Prevention, National Cancer Center/National Clinical Research Center for Cancer/Cancer Hospital, Chinese Academy of Medical Sciences and Peking Union Medical College, 17 South Panjiayuan Lane, Chaoyang District, Beijing 100021, P. R. China

Full list of author information is available at the end of the article
}

significantly higher risk of developing cancer than the general population $[4,5]$.

Familial cluster data reveals that there is important interaction between inherited genes and shared environmental factors, and cancer outcomes. Friedman et al. indicated that the siblings of long-term childhood cancer survivors have an increased risk of cancer [6]. Similar to parents and their children, siblings share genetic and environmental factors. However, comparing to the case of parents and children, siblings are more likely to develop similar lifestyle and dietary habits, especially siblings of the same sex. Therefore, the risk of cancer of an individual is more strongly associated with the cancer history of the siblings rather than the parents [5]. However,

(c) The Author(s). 2021 Open Access This article is licensed under a Creative Commons Attribution 4.0 International License, which permits use, sharing, adaptation, distribution and reproduction in any medium or format, as long as you give appropriate credit to the original author(s) and the source, provide a link to the Creative Commons licence, and indicate if changes were made. The images or other third party material in this article are included in the article's Creative Commons licence, unless indicated otherwise in a credit line to the material. If material is not included in the article's Creative Commons licence and your intended use is not permitted by statutory regulation or exceeds the permitted use, you will need to obtain permission directly from the copyright holder. To view a copy of this licence, visit http://creativecommons.org/licenses/by/4.0/ The Creative Commons Public Domain Dedication waiver (http://creativecommons.org/publicdomain/zero/1.0/) applies to the data made available in this article, unless otherwise stated in a credit line to the data. 
among Chinese population, few studies investigated and analyzed the characteristics of siblings with cancers.

The aim of our study is to evaluate the probability of siblings developing the same cancer types or cancers from the same systemic origin, and to assess their age of diagnosis. We also aim to develop recommendations on opportunistic screening for early detection of cancer for individuals whose siblings have histories of cancers.

\section{Materials and methods}

\section{Study population}

During their physical examination visit to the Department of Cancer Prevention at the Cancer Hospital of the Chinese Academy of Medical Sciences from January 2008 to December 2019, 43,300 individuals were asked if they have at least two siblings (including themselves) who had been diagnosed with cancer. The diagnosed age (year) and cancer types of siblings need to be confirmed again by calling to first degree other family member by participant. Participants were included in our study if (1) two or more siblings from the same biological parents had been diagnosed with cancer, and (2) the siblings' ages at diagnosis of cancer were available. The excluding criteria include: (1) primary cancer sites of any family member were unknown; (2) age of any family member with cancer at diagnosis was unavailable; (3) The participant's father or mother was diagnosed with cancer. (4) Participants had long-term occupational exposure. A total of 1270 sibling pairs from 766 families were included in the study.

\section{Statistical analysis}

In this study, cancer from the same systemic origin includes digestive system cancer, reproductive system cancer, respiratory system cancer, endocrine system cancer, circulatory system cancer, and urinary system cancer. Digestive system cancer includes tongue cancer, esophageal cancer, stomach cancer, colorectal cancer, liver cancer, pancreatic cancer and gallbladder cancer. Reproductive system cancer includes breast cancer, endometrial cancer, ovarian cancer, cervical cancer, prostate cancer, testicular cancer and vulvar cancer. Respiratory system cancer includes nasopharyngeal cancer, laryngeal cancer and lung cancer. Endocrine system cancer includes thyroid cancer. Circulatory system cancer includes malignant lymphoma, leukemia and multiple myeloma. Urinary system cancer includes kidney cancer, ureter cancer and bladder cancer. Differences between ages of diagnosis of siblings in sibling-pairs were calculated and analyzed with one-way ANOVA test or independent student's t-test. Categorical variables were presented as number (percentage) and were compared using the chi-square test. Data analyses were conducted with SPSS software package, version 16.0 (SPSS Inc., Chicago, IL, USA).

\section{Results}

\section{General information}

Among 766 families with two or more siblings diagnosed with cancer, 586 (76.5\%) families had 2 siblings with cancer, 143 (18.7\%) had 3, 29 (3.8\%) had 4, 7 (0.9\%) had 5 , and $1(0.1 \%)$ had 6 . These siblings were divided into sibling pairs. There were 367 pairs of brothers (Bropairs) from 216 families, 368 pairs of sisters (Sis-pairs) from 237 families, and 535 pairs of brother-and-sister (BroSis-pairs) from 313 families.

\section{Cancer types}

The proportions of cancer diagnosis in Bro-pairs, Sispairs and BroSis-pairs are shown in Table 1. As expected, lung cancer was the most common cancer among Bro-pairs and male from BroSis-pairs. For Sispairs and female from BroSis-pairs, breast cancer was the most common. The 5 most common cancer types in Bro-pairs were lung cancer, stomach cancer, liver cancer, colorectal cancer and esophageal cancer, which was consistent with male from BroSis-pairs. For Sis-pairs, the five most common cancer types were breast cancer, lung cancer, colorectal cancer, thyroid cancer and liver cancer. The result was also consistent with females in the BroSis-pairs, except the fourth most common cancer type being stomach cancer instead of thyroid cancer.

\section{Age of diagnosis}

The mean age of cancer diagnosis was $61.8 \pm 12.1$ for Bro-pairs, $57.8 \pm 12.2$ for Sis-pairs, and $60.9 \pm 11.6$ for BroSis-pairs. For sis-pairs, the mean age of diagnosis is significantly younger than the other two groups (both $P<0.001$ ).

In each group (Bro-pair, Sis-pair and BroSis-pair), the 30-year range of age of diagnosis with the highest percentage of diagnosis was analyzed, according to the data from Table 2. In Bro-pairs, $80.2 \%$ of brothers developed cancer between the age of 46 and 75 . In Sis-pairs, $75.4 \%$ of sisters developed cancer between 41 and 70 . In BroSis-pairs, $83.7 \%$ of brothers developed cancer between 46 and 75, while $79.3 \%$ of sisters developed cancer during the same 30 -year range.

The 5-year range of age of diagnosis with the highest percentage of diagnosis for bro-pairs was 66-70 years old, comparing to 56-60 years old for the Sis-pair group. For the BroSis-pairs, the range was 56-60 for brothers, and 61-65 for sisters. However, it should be noted that within the bro-pairs, there is only 1 less case within the $56-60$ years old group comparing to the 66-70 years old group (Table 2). 


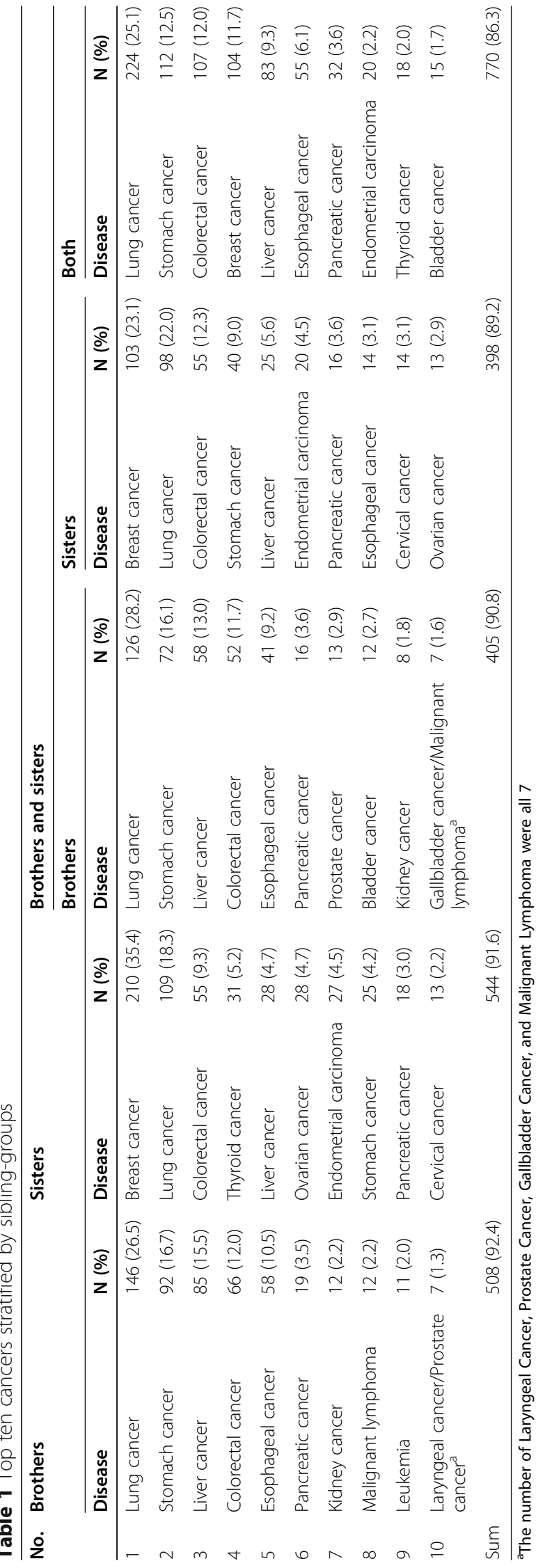


Table 2 Age of diagnosis stratified by sibling-groups

\begin{tabular}{|c|c|c|c|c|c|c|}
\hline \multirow[t]{2}{*}{ Age } & \multirow{2}{*}{$\begin{array}{l}\text { Brothers } \\
\mathrm{N}(\%)\end{array}$} & \multirow{2}{*}{$\begin{array}{l}\text { Sisters } \\
\mathrm{N}(\%)\end{array}$} & \multicolumn{3}{|c|}{ Brother-and-sister N (\%) } & \multirow[t]{2}{*}{ All N (\%) } \\
\hline & & & Brothers & Sisters & Both & \\
\hline$\leq 30$ & $5(0.9)$ & $7(1.2)$ & $3(0.7)$ & $4(0.9)$ & $7(0.8)$ & $19(0.9)$ \\
\hline $31 \sim 35$ & $8(1.5)$ & $16(2.7)$ & $9(2.0)$ & $4(0.9)$ & $13(1.4)$ & $37(1.8)$ \\
\hline $36 \sim 40$ & $14(2.5)$ & $24(4.0)$ & $5(1.1)$ & $22(4.9)$ & $27(3.0)$ & $65(3.2)$ \\
\hline $41 \sim 45$ & $24(4.4)$ & $61(10.3)$ & $20(4.5)$ & $26(5.8)$ & $46(5.2)$ & $131(6.4)$ \\
\hline $46 \sim 50$ & $53(9.6)$ & $83(14.0)$ & $32(7.2)$ & $48(10.8)$ & $80(9.0)$ & $216(10.6)$ \\
\hline $51 \sim 55$ & $66(12.0)$ & $72(12.1)$ & $70(15.7)$ & $57(12.8)$ & $127(14.2)$ & $265(13.0)$ \\
\hline $56 \sim 60$ & $85(15.5)$ & $89(15.0)$ & $85(19.1)$ & $53(11.9)$ & $138(15.5)$ & $312(15.3)$ \\
\hline $61 \sim 65$ & $79(14.3)$ & $83(14.0)$ & $65(14.6)$ & $72(16.2)$ & $137(15.4)$ & $299(14.7)$ \\
\hline $66 \sim 70$ & $86(15.6)$ & $60(10.1)$ & $62(13.9)$ & $67(15.0)$ & $129(14.5)$ & $275(13.5)$ \\
\hline $71 \sim 75$ & $72(13.1)$ & $56(9.4)$ & $59(13.2)$ & $57(12.8)$ & $116(13.0)$ & $244(12.0)$ \\
\hline $76 \sim 80$ & $34(6.2)$ & $30(5.0)$ & $20(4.5)$ & $24(5.4)$ & $44(4.9)$ & $108(5.3)$ \\
\hline $81 \sim 85$ & $15(2.7)$ & $11(1.9)$ & $10(2.2)$ & $10(2.2)$ & $20(2.2)$ & $46(2.3)$ \\
\hline $86 \sim 90$ & $8(1.5)$ & $2(0.3)$ & $6(1.3)$ & $1(0.2)$ & $7(0.8)$ & $17(0.9)$ \\
\hline$>90$ & $1(0.2)$ & $0(0)$ & $0(0)$ & $1(0.2)$ & $1(0.1)$ & $2(0.1)$ \\
\hline Total & $550(100)$ & $594(100)$ & 446 (100) & $446(100)$ & $892(100)$ & $2036(100$ \\
\hline
\end{tabular}

\section{Category of cancer from systemic origins}

As shown in Tables 3, 203 out of 367 (55.3\%) Bro-pairs were diagnosed with cancers from the same systemic origin (same-origin cancers). The digestive system cancer $(157,77.3 \%)$ was the most common. The second most common was respiratory system cancer (44, $21.7 \%$ ), while cancer from other cancer origins only accounted for $1 \%$ (2 cases). Out of 368, 188 (51.1\%) Sispairs were diagnosed with the same-origin cancers, which was slightly lower than Bro-pairs. Among sispairs, the reproductive system cancer $(114,60.6 \%)$ was the most common, followed by digestive $(36,19.1 \%)$, respiratory $(32,8.7 \%)$ and endocrine $(6,3.2 \%)$ system cancers. Only 192 pairs out of 535 (36.0\%) BroSis-pairs were diagnosed with same-origin cancers, which was significantly lower than both Bro-pair $(P<0.001)$ and Sispair $(P<0.001)$. Among the BroSis-pairs, the most common one was digestive system cancer (126, 65.6\%), followed by respiratory system cancers (51, 26.6\%), reproductive system cancers $(10,5.2 \%)$ and other cancer origins $(5,2.6 \%)$.

\section{Types of cancer}

As shown in Table 4, among 367 Bro-pairs, 103 (28.1\%) were diagnosed with the same cancer type. The most common one was lung cancer, followed by liver cancer, stomach cancer, esophageal cancer and colorectal cancer. Among 368 Sis-pairs, 137 (37.2\%) were diagnosed with the same cancer type. The most common ones were breast cancer, lung cancer, cervical cancer, liver cancer, thyroid cancer, and colorectal cancer. For BroSis-pairs, only 101 (18.9\%) pairs developed the same type of cancer. The 5 most common cancer types were identical as the Bro-pairs. The proportion of the same cancer type of Sis-pairs was the highest, followed by Bro-pairs $(P=0.010)$ and BroSis-pairs $(P<0.001)$.

Table 3 Sibling-pairs with cancers from the same systemic origin, stratified by sibling-groups

\begin{tabular}{|c|c|c|c|c|}
\hline & \multicolumn{4}{|c|}{ Same system N (\%) } \\
\hline & Brother & Sisters & Brother-and-sister & All \\
\hline Digestive system & $157(77.3)$ & $36(19.2)$ & $126(65.6)$ & $319(54.7)$ \\
\hline Respiratory system & $44(21.7)$ & $32(17.0)$ & $51(26.6)$ & $127(21.8)$ \\
\hline Reproductive system & $1(0.5)$ & $114(60.6)$ & $10(5.2)$ & $125(21.5)$ \\
\hline Blood system & $1(0.5)$ & 0 & $1(0.5)$ & $2(0.3)$ \\
\hline Endocrine system & 0 & $6(3.2)$ & $3(1.6)$ & $9(1.5)$ \\
\hline Urinary system & 0 & 0 & $1(0.5)$ & $1(0.2)$ \\
\hline $\operatorname{Sum}(A / B)^{a}$ & $203 / 367(55.3)$ & $188 / 368(51.1)$ & $192 / 535(36.0)$ & $583 / 1270(45.9)$ \\
\hline
\end{tabular}

\footnotetext{
${ }^{a} A$, the sum of the sibling-pairs with cancers from same systemic origin; $B$, the sum of the sibling-pairs with cancers
} 
Table 4 Sibling-pairs with the same type of cancer, stratified by sibling-pairs

\begin{tabular}{|c|c|c|c|c|c|c|}
\hline \multirow[t]{2}{*}{ No } & \multicolumn{2}{|l|}{ Brothers } & \multicolumn{2}{|l|}{ Sisters } & \multicolumn{2}{|l|}{ Brother-and-sister } \\
\hline & Disease & N (\%) & Disease & $\mathrm{N}(\%)$ & Disease & $\mathrm{N}(\%)$ \\
\hline 1 & Lung Cancer & $37(35.9)$ & Breast Cancer & $77(56.2)$ & Lung Cancer & $46(45.5)$ \\
\hline 2 & Liver Cancer & $22(21.4)$ & Lung Cancer & $29(21.2)$ & Stomach Cancer & $15(14.8)$ \\
\hline 3 & Stomach Cancer & $19(18.4)$ & Cervical Cancer & $7(5.1)$ & Colorectal Cancer & $14(13.9)$ \\
\hline 4 & Esophageal Cancer & $13(12.6)$ & Liver Cancer & $5(3.6)$ & Liver Cancer & $11(10.9)$ \\
\hline 5 & Colorectal Cancer & $9(8.7)$ & Thyroid Cancer & $5(3.6)$ & Esophageal Cancer & $6(5.9)$ \\
\hline 6 & Nasopharyngeal Carcinoma & $1(1.0)$ & Colorectal Cancer & $5(3.6)$ & Thyroid Cancer & $3(3.0)$ \\
\hline 7 & Prostate Cancer & $1(1.0)$ & Ovarian Cancer & $4(2.9)$ & Pancreatic Cancer & $3(3.0)$ \\
\hline 8 & Lymphoma & $1(1.0)$ & Esophageal Cancer & $2(1.5)$ & Breast Cancer & $1(1.0)$ \\
\hline 9 & - & - & Pancreatic Cancer & $2(1.5)$ & Myeloma & $1(1.0)$ \\
\hline 10 & - & - & Stomach Cancer & $1(0.7)$ & Cholangiocarcinoma & $1(1.0)$ \\
\hline \multicolumn{2}{|c|}{$\operatorname{Sum}(A / B)^{a}$} & $\begin{array}{l}103 / 367 \\
(28.1)\end{array}$ & & $137 / 368(37.2)$ & & $101 / 535(18.9)$ \\
\hline
\end{tabular}

${ }^{a} A$, the sum of the sibling-pairs with same type of cancer; $B$, the sum of the sibling-pairs with cancer

\section{Differences between ages of diagnosis}

For each group, differences between ages of diagnosis of two siblings (age differences) were calculated (Table 5). The most common age-difference group for all three sibling-pair groups was 1-5 years. For Bro-pairs, this age-difference group accounted for $30.8 \%$ of cases, while the percentage was comparable for sis-pairs (32.6\%) and BroSis-pairs (30.1\%), with no significant difference between groups (all $P>0.05$ ). When considering the age differences within 10 years, the result across sibling-pair groups were also not significant (all $P>0.05$ ) difference, with $224(61.1 \%)$ in Bro-pairs, 231 (62.8\%) in Sis-pairs and $334(62.4 \%)$ in BroSis-pairs. For all sibling-pair groups, more than three quarters developed diseases within 15 years of age differences $(79.0 \%$ for Bro-pairs, 76.3\% for Sis-pairs, 77.9\% for BroSis-pairs).

For cancer from the same systemic origin (Table 5), $69.6 \%$ of Sis-pairs developed diseases within 10 years of age differences, which was significantly higher than cancer from different systemic origins $(55.6 \%, P=0.005)$. For Bro-pairs, $63.5 \%$ developed same-origin cancers within 10 years of age differences, which was not significantly different than bropairs who developed different-origin cancers $(57.9 \%, P>$ 0.05). Similarly, $65.1 \%$ of BroSis-pairs developed sameorigin cancers within 10 years of age differences, which was not significantly different than BroSis-pairs who developed different-origin cancers $(60.9 \%, P>0.05)$.

When considering cancer types (Table 6), for age differences less than 10 years, the proportion of all siblingpair groups who developed same cancer types were higher than the groups who developed different cancer types $(66.1 \%$ vs $59.0 \%$ for Bro-pair, $69.1 \%$ vs $59.1 \%$ for Sis-pairs, and $70.3 \%$ vs $60.6 \%$ for BroSis-pair), but these differences were not significant (all $P>0.05$ ).

\section{Discussion}

By analyzing medical records collected over 12 years, this pioneer study aims to analyze whether cancer histories

Table 5 Differences in age of diagnosis to systemic origins of cancers, stratified by sibling-pair groups

\begin{tabular}{|c|c|c|c|c|c|c|c|c|c|c|c|c|}
\hline \multirow{2}{*}{$\begin{array}{l}\text { Age } \\
\text { difference }\end{array}$} & \multicolumn{3}{|c|}{ Brother N (\%) } & \multicolumn{3}{|c|}{ Sister N (\%) } & \multicolumn{3}{|c|}{ Brother-and-sister N (\%) } & \multicolumn{3}{|l|}{ All N (\%) } \\
\hline & $\begin{array}{l}\text { Same } \\
\text { system }\end{array}$ & $\begin{array}{l}\text { Different } \\
\text { system }\end{array}$ & Both & $\begin{array}{l}\text { Same } \\
\text { system }\end{array}$ & $\begin{array}{l}\text { Different } \\
\text { system }\end{array}$ & Both & $\begin{array}{l}\text { Same } \\
\text { system }\end{array}$ & $\begin{array}{l}\text { Different } \\
\text { system }\end{array}$ & Both & $\begin{array}{l}\text { Same } \\
\text { system }\end{array}$ & $\begin{array}{l}\text { Different } \\
\text { system }\end{array}$ & Both \\
\hline 0 & $16(7.9)$ & $14(8.5)$ & $30(8.2)$ & $17(9.0)$ & $13(7.2)$ & $30(8.2)$ & $14(7.3)$ & $17(5.0)$ & $31(5.8)$ & $47(8.1)$ & $44(6.4)$ & $91(7.2)$ \\
\hline $1-5$ & $66(32.5)$ & $47(28.7)$ & $113(30.8)$ & $70(37.2)$ & $50(27.8)$ & $120(32.6)$ & $59(30.7)$ & $102(29.7)$ & $161(30.1)$ & $195(33.4)$ & $199(29.0)$ & $394(31.0)$ \\
\hline $6-10$ & $47(23.1)$ & $34(20.7)$ & $81(22.1)$ & $44(23.4)$ & $37(20.6)$ & $81(22.0)$ & $52(27.1)$ & $90(26.2)$ & $142(26.5)$ & $143(24.5)$ & $161(23.4)$ & $304(23.9)$ \\
\hline $11-15$ & 38 (18.7) & $28(17.1)$ & $66(18.0)$ & $21(11.2)$ & $29(16.1)$ & 50 (13.6) & 30 (15.6) & $53(15.5)$ & 83 (15.5) & 89 (15.3) & $110(16.0)$ & 199 (15.7) \\
\hline $16-20$ & $15(7.4)$ & $15(9.1)$ & $30(8.2)$ & $21(11.2)$ & $20(11.1)$ & $41(11.1)$ & $16(8.3)$ & 37 (10.8) & $53(9.9)$ & $52(8.9)$ & $72(10.5)$ & $124(9.8)$ \\
\hline $21-25$ & $12(5.9)$ & $12(7.3)$ & $24(6.5)$ & $10(5.3)$ & $17(9.5)$ & $27(7.3)$ & $11(5.7)$ & $21(6.1)$ & $32(6.0)$ & $33(5.7)$ & $50(7.3)$ & $83(6.5)$ \\
\hline $26-30$ & $5(2.5)$ & $7(4.3)$ & $12(3.2)$ & $3(1.6)$ & $6(3.3)$ & $9(2.5)$ & $7(3.7)$ & $14(4.1)$ & $21(3.9)$ & $15(2.6)$ & $27(3.9)$ & $42(3.3)$ \\
\hline$>30$ & $4(2.0)$ & $7(4.3)$ & $11(3.0)$ & $2(1.1)$ & $8(4.4)$ & $10(2.7)$ & $3(1.6)$ & $9(2.6)$ & $12(2.3)$ & $9(1.5)$ & $24(3.5)$ & $33(2.6)$ \\
\hline Total & $203(100)$ & $164(100)$ & $367(100)$ & $188(100)$ & $180(100)$ & $368(100)$ & $192(100)$ & $343(100)$ & $535(100)$ & $583(100)$ & $687(100)$ & $1270(100)$ \\
\hline
\end{tabular}


Table 6 Difference in age of diagnosis to cancer types, stratified by sibling-pair groups

\begin{tabular}{|c|c|c|c|c|c|c|c|c|}
\hline \multirow{2}{*}{$\begin{array}{l}\text { Age } \\
\text { difference }\end{array}$} & \multicolumn{2}{|l|}{ Brother N (\%) } & \multicolumn{2}{|l|}{ Sister N (\%) } & \multicolumn{2}{|c|}{ Brother-and-sister N (\%) } & \multicolumn{2}{|l|}{ All N (\%) } \\
\hline & Same cancer & Different cancer & Same cancer & Different cancer & Same cancer & Different cancer & Same cancer & Different cancer \\
\hline 0 & $8(7.8)$ & $22(8.3)$ & $13(9.5)$ & $17(7.4)$ & $8(7.9)$ & $23(5.3)$ & $29(8.5)$ & $62(6.8)$ \\
\hline $1-5$ & $38(36.9)$ & $75(28.4)$ & $54(39.4)$ & $66(28.6)$ & $35(34.7)$ & $126(29.0)$ & $127(37.2)$ & $267(28.7)$ \\
\hline $6-10$ & $22(21.4)$ & $59(22.3)$ & $28(20.4)$ & $53(22.9)$ & $28(27.7)$ & $114(26.3)$ & 78 (22.9) & $226(24.3)$ \\
\hline $11-15$ & 19 (18.4) & $47(17.8)$ & $14(10.2)$ & $36(15.6)$ & $13(12.9)$ & $70(16.1)$ & $46(13.5)$ & $153(16.4)$ \\
\hline $16-20$ & $9(8.7)$ & $21(8.0)$ & $16(11.7)$ & $25(10.8)$ & $5(4.9)$ & $48(11.1)$ & $30(8.8)$ & $94(10.1)$ \\
\hline $21-25$ & $3(2.9)$ & $21(8.0)$ & $8(5.8)$ & $19(8.2)$ & $7(6.9)$ & $25(5.8)$ & $18(5.3)$ & $65(7.0)$ \\
\hline $26-30$ & $1(1.0)$ & $11(4.2)$ & $2(1.5)$ & $7(3.0)$ & $3(3.0)$ & $18(4.1)$ & $6(1.7)$ & $36(3.9)$ \\
\hline$>30$ & $3(2.9)$ & $8(3.0)$ & $2(1.5)$ & $8(3.5)$ & $2(2.0)$ & $10(2.3)$ & $7(2.1)$ & $26(2.8)$ \\
\hline Total & 103 (100) & $264(100)$ & 137 (100) & $231(100)$ & 101 (100) & 434 (100) & $341(100)$ & 929 (100) \\
\hline
\end{tabular}

of siblings should be an indicator for early opportunistic screening for early detection of cancer for such individuals. Overall, the most common cancer types and their proportions among male and female is consistent with the data of China from the 2018 Globocan [7].

More than half of Bro-pairs (55.3\%) or Sis-pairs (51.1\%) had cancer from same systemic origin, and more than a quarter of Bro-pairs (28.1\%) and Sis-pairs (37.2\%) developed the same type of cancer. Therefore, men whose brother is diagnosed with cancer should pay special attention to opportunistic screening for cancers from the same systemic origin, especially if the brother is diagnosed with lung cancer, liver cancer, stomach cancer, esophageal cancer or colorectal cancer. For women whose sister is diagnosed with cancer, likewise, she should consider participating in opportunistic screening for same-origin cancers, especially if the sister is diagnosed with breast cancer, lung cancer, cervical cancer, liver cancer, colorectal cancer or thyroid cancer. Although only $36.0 \%$ or $18.9 \%$ of siblings from Bro-Sis pairs developed same-origin cancers or same types of cancers, individual whose sibling is diagnosed with cancer should pay special attention to early screening of lung cancer or digestive system cancer if the sibling is diagnosed with these cancers.

Tobacco smoke (first- and second-hand) exposure, alcohol consumption and obesity are important risk factors for cancers worldwide [8]. Smoking is an especially important risk factor for lung cancer [9], while alcohol consumption is a vital risk factor for liver cancer [10]. In addition, chronic infection with hepatitis $B$ virus or hepatitis $C$ virus is the predominant cause of liver cancer [11], while infection with bacterium helicobacter pylori is the main risk factor for stomach cancer [12]. Dietary habit is also associated with several digestive system cancers. Low intake of fruits and vegetables increases risks of stomach cancer and esophageal cancer [13, 14], while high vegetables and fruits intake may protect individuals against esophagus cancer [15], colorectal cancer [16], and breast cancer [17]. Consumption of hot food and beverages is associated with an increased risk of esophageal cancer [18], while a high intake of dietary fiber, in particular cereal fiber and whole grains, reduces the risk of colorectal cancer $[19,20]$.

Special attention should be paid to thyroid cancer, as its incidence rate is increasing rapidly worldwide, especially in women, whose risk is 3 times higher than their male counterparts [7]. It is now the fourth most common cancer among Chinese women, which is similar to our study. Different than other cancers, Thyroid cancer is disproportionally diagnosed among younger population [21]. In this study, the median age of diagnosis of thyroid cancer is 48 years old, and $69.0 \%$ of incident cases occur in patients under 50 years. Established risk factors for thyroid cancer includes family history, obesity, alcohol and tobacco consumption, and ionizing radiation [21].

Therefore, changes in lifestyle and dietary habit play an important role in reducing the incidence of all cancers. As siblings share similar inherited genes, the changes in lifestyle are especially important for an individual if the sibling is diagnosed with cancer.

Hereditary tumor syndromes, which are caused by an inactivating mutation in a single crucial gene, increase the risk of cancers. Approximately $3-5 \%$ of patients with breast cancer and $8-17 \%$ of patients with ovarian cancer can attribute the cancer to germline pathogenic variants in the BRCA1 and BRCA2 genes [22-25], which is called the hereditary breast-ovarian cancer (HBOC) syndrome [24]. Individuals carrying mutations in BRCA1/BRCA are associated with a higher lifetime risk of up to 60$85 \%$ for breast cancer, and $17-39 \%$ for ovarian cancer by the age of 70 [26-28]. When an individual is found to have a germline BRCA1/BRCA2 mutation in HBOC or a DNA mis-match repair gene mutation in Lynch syndrome [29], the individual should inform their at-risk family members about the option of presymptomatic DNA testing. Due to the high cost of genetic testing and 
lack of informed consent from other family members, only a few participants underwent genetic testing, which reflects the low prevalence of genetic testing among Chinese population.

However, in this study, for siblings in sibling-pairs diagnosed with breast cancer, ovarian cancer or colorectal cancer, the majority of differences of ages-at-diagnosis was within 10 years. Among 77 Sis-pairs with breast cancer, the average age of diagnosis was 54.8. Among them, $54.5 \%$ of the ages-at-diagnosis differences between sisters were within 5 years, and $75.3 \%$ within 10 years. For 4 sis-pairs with ovarian cancer, the age differences were all within 10 years.

Across all sibling-pair groups, 28 sibling-pairs were diagnosed with colorectal cancer, and $32.1 \%$ of the pairs had age differences of less than 5 years, while $75.0 \%$ had age differences of less than 10 years.

Individuals with identified pathogenic variants in the BRCA1/BRCA2 gene can benefit from cancer riskreducing strategies.

Considering that more than a quarter of Bro-pairs and Sis-pairs, and nearly 20\% BroSis-pairs developed the same type of cancer, and that in these sibling-pairs with the same type of cancer, over $65 \%$ were diagnosed within the age difference of 10 years, genetic services are essential for individuals who has a sibling diagnosed with cancer.

Early diagnosis and treatment of cancer is very important to prolong the survival time of patients. In three sibling-pair groups, sibling-pairs with less than 5 years of age differences account for $35.9-40.8 \%$ of all pairs, while those with less than 10 years of age differences account for $61.1-62.8 \%$. Usually, the development of cancer from precancerous lesions takes years, if not decades. Therefore, after a sibling has been diagnosed with cancer, the other sibling should be recommended to participate in opportunistic screening for early detection of cancer every year.

The most important strength of our study is its large sample size, which was collected during physical examination over 12 years. The study has several limitations. First, only individuals who underwent physical examination in one location were included in the study. Second, the ages of diagnosis were collected through surveys and face-to-face interviews, which may result in recall bias or information bias. However, the diagnosed age and cancer types of siblings were confirmed twice by firstdegree relatives. In general, if the family member gets cancer, the first-degree relatives will take the information very seriously. Therefore, the recall bias is unlikely to have resulted in too much effect of the results. In addition, hospitals in China are organized according to a 3-tier system that recognizes a hospital's ability to provide medical care, medical education, and conduct medical research. Based on this, hospitals are designated as Primary, Secondary or Tertiary institutions [30]. Tertiary hospitals round up the list as comprehensive or general hospitals at the city, provincial or national level. They are responsible for providing specialist health services, perform a bigger role with regard to medical education and scientific research and they serve as medical hubs providing care to multiple regions. In China, the patient tends to visited the tertiary hospital to confirm the disease, if he or she was diagnosed with the cancer in other level hospitals. Thus, cancer diagnosis information is relatively reliable. Third, no other risk factors or potential confounders were evaluated, which could cause confounding and selection bias. Finally, genetic testing for the siblings was not conducted. Further studies are needed to include multi-center samples, adjust for potential confounders and test for genomic DNA sequence.

In conclusion, by analyzing shared characteristics of sibling-pairs with cancers, this study concluded several recommendations for opportunistic screening for individuals whose siblings are diagnosed with cancers. When an individual's sibling is diagnosed with cancer, the individual should consider participating in opportunistic screening each year, especially for lung cancer and digestive system cancers for both sexes. In addition, for female, breast cancer, cervical cancer and thyroid cancer should also be screened early. Furthermore, genetic services are essential for individuals who have siblings with cancer.

\section{Abbreviations}

Bro: Brother; Sis: Sister; BroSis: Brother-and-sister; HBOC: Hereditary breastovarian cancer

\section{Acknowledgements}

We thank Xunwen (Aaron) Zou (Macalester College) for his help in revising the manuscript.

\section{Authors' contributions}

Study concepts and Study design: JL, KZ and ZX; Data acquisition, analysis, interpretation and statistical analysis: $J L, J Y$ and $Y L$; Manuscript preparation and editing: $Y J$ and $J L_{;}$Manuscript review: $J L$ and $K Z ; A l l$ authors read and approved the final manuscript.

\section{Funding}

The study was supported by grants from the CAMS Innovation Fund for Medical Sciences (2017-I2M-1-006).

\section{Availability of data and materials}

The datasets used and analyzed during the current study are available from the corresponding author on reasonable request.

\section{Declarations}

Ethics approval and consent to participate

The study was performed according to the guidelines of the Helsinki declaration. All participants provided written informed consent. This study was approved by the ethical committee board of Cancer Hospital/Institute of Chinese Academy of Medical Sciences. 


\section{Consent for publication}

Not applicable.

\section{Competing interests}

The authors declare that they have no competing interests.

\section{Author details}

'Department of Cancer Prevention, National Cancer Center/National Clinical Research Center for Cancer/Cancer Hospital, Chinese Academy of Medical Sciences and Peking Union Medical College, 17 South Panjiayuan Lane, Chaoyang District, Beijing 100021, P. R. China. ${ }^{2}$ Department of Cancer Epidemiology, National Cancer Center/National Clinical Research Center for Cancer/Cancer Hospital, Chinese Academy of Medical Sciences and Peking Union Medical College, Beijing 100021, P.R. China. ${ }^{3}$ School of Population Medicine and Public Health, Chinese Academy of Medical Sciences and Peking Union Medical College, Beijing 100730, China. ${ }^{4}$ College of Life Sciences, Hebei University, Baoding 071002, P.R. China.

\section{Received: 25 January 2021 Accepted: 28 August 2021}

\section{Published online: 15 September 2021}

\section{References}

1. Bray F, Ferlay J, Soerjomataram I, Siegel RL, Torre LA, Jemal A. Global cancer statistics 2018: GLOBOCAN estimates of incidence and mortality worldwide for 36 cancers in 185 countries. CA Cancer J Clin. 2018;68(6):394-424. https://doi.org/10.3322/caac.21492.

2. Yoon PW, Scheuner MT, Peterson-Oehlke KL, Gwinn M, Faucett A, Khoury MJ. Can family history be used as a tool for public health and preventive medicine? Genet Med. 2002;4(4):304-10. https://doi.org/10.1097/00125817-2 00207000-00009.

3. Guttmacher AE, Collins FS, Carmona RH. The family history--more important than ever. N Engl J Med. 2004;351(22):2333-6. https://doi.org/10.1056/ NEJMsb042979.

4. Song M, Camargo MC, Weinstein SJ, Best AF, Mannisto S, Albanes D, et al, Family history of cancer in first-degree relatives and risk of gastric cancer and its precursors in a Western population. Gastric Cancer. 2018;21(5):72937. https://doi.org/10.1007/s10120-018-0807-0.

5. Zhang Y, Shu XO, Gao YT, Ji BT, Yang G, Li HL, et al. Family history of cancer and risk of lung cancer among nonsmoking Chinese women. Cancer Epidemiol Biomark Prev. 2007;16(11):2432-5. https://doi.org/10.1158/10559965.EPI-07-0398.

6. Friedman DL, Kadan-Lottick NS, Whitton J, Mertens AC, Yasui Y, Liu Y, et al. Increased risk of cancer among siblings of long-term childhood cancer survivors: a report from the childhood cancer survivor study. Cancer Epidemiol Biomark Prev. 2005;14(8):1922-7. https://doi.org/10.1158/10559965.EPI-05-0066.

7. Globocan 2018: latest global cancer data. Lyon (France): International Agency for Research on Cancer. Available from: https:/gco.iarc.fr/today/

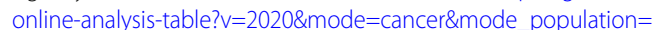
continents\&population $=900 \&$ populations $=160 \&$ key $=$ asr $\&$ sex $=0 \&$ cancer $=$ $39 \&$ type $=0 \&$ statistic $=5 \&$ prevalence $=0 \&$ population_group=0\&ages_group $\%$ 5B\%5D=0\&ages_group-0-3.

8. Boffetta P, Hashibe M. Alcohol and cancer. Lancet Oncol. 2006;7(2):149-56. https://doi.org/10.1016/S1470-2045(06)70577-0.

9. McRobbie H, Kwan B. Tobacco use disorder and the lungs. Addiction. 2021; 116(9):2559-71. https://doi.org/10.1111/add.15309.

10. Turati F, Galeone C, Rota M, Pelucchi C, Negri E, Bagnardi V, et al. Alcohol and liver cancer: a systematic review and meta-analysis of prospective studies. Ann Oncol. 2014;25(8):1526-35. https://doi.org/10.1093/annonc/ mdu020.

11. Chuang SC, La Vecchia C, Boffetta P. Liver cancer: descriptive epidemiology and risk factors other than HBV and HCV infection. Cancer Lett. 2009;286(1): 9-14. https://doi.org/10.1016/j.canlet.2008.10.040.

12. Buti L, Ruiz-Puig C, Sangberg D, Leissing TM, Brewer RC, Owen RP, et al. CagA-ASPP2 complex mediates loss of cell polarity and favors $\mathrm{H}$. pylori colonization of human gastric organoids. Proc Natl Acad Sci U S A. 2020; 117(5):2645-55. https://doi.org/10.1073/pnas.1908787117.

13. Palladino-Davis AG, Mendez BM, Fisichella PM, Davis CS. Dietary habits and esophageal cancer. Dis Esophagus. 2015;28(1):59-67. https://doi.org/1 $0.1111 /$ dote.12097
14. Ferro A, Costa AR, Morais S, Bertuccio P, Rota M, Pelucchi C, et al. Fruits and vegetables intake and gastric cancer risk: a pooled analysis within the stomach cancer pooling project. Int J Cancer. 2020;147(11):3090-101. https://doi.org/10.1002/ijc.33134.

15. Du H, Li L, Bennett D, Yang L, Guo Y, Key TJ, et al. Fresh fruit consumption and all-cause and cause-specific mortality: findings from the China Kadoorie biobank. Int J Epidemiol. 2017;46(5):1444-55. https://doi.org/10.1093/ije/ dyx042.

16. Lee J, Shin A, Oh JH, Kim J. Colors of vegetables and fruits and the risks of colorectal cancer. World J Gastroenterol. 2017;23(14):2527-38. https://doi. org/10.3748/wjg.v23.i14.2527.

17. Shamshirian A, Heydari K, Shams Z, Aref AR, Shamshirian D, Tamtaji OR, et al. Breast cancer risk factors in Iran: a systematic review \& meta-analysis. Horm Mol Biol Clin Investig. 2020;41(4). https://doi.org/10.1515/hmbci-20200021.

18. Andrici J, Eslick GD. Hot food and beverage consumption and the risk of esophageal Cancer: a Meta-analysis. Am J Prev Med. 2015;49(6):952-60. https://doi.org/10.1016/j.amepre.2015.07.023.

19. Chapkin RS, Navarro SL, Hullar MAJ, Lampe JW. Diet and gut microbes act coordinately to enhance programmed cell death and reduce colorectal Cancer risk. Dig Dis Sci. 2020;65(3):840-51. https://doi.org/10.1007/s10620-02 0-06106-8.

20. Aune D, Chan DS, Lau R, Vieira R, Greenwood DC, Kampman E, et al. Dietary fibre, whole grains, and risk of colorectal cancer: systematic review and dose-response meta-analysis of prospective studies. BMJ. 2011;343(nov10 1): d6617. https://doi.org/10.1136/bmj.d6617.

21. Seib CD, Sosa JA. Evolving understanding of the epidemiology of thyroid Cancer. Endocrinol Metab Clin N Am. 2019;48(1):23-35. https://doi.org/10.1 016/j.ecl.2018.10.002.

22. Hemminki K, Granstrom C. Familial breast cancer: scope for more susceptibility genes? Breast Cancer Res Treat. 2003;82(1):17-22. https://doi. org/10.1023/B:BREA.0000003871.38587.8b.

23. Serova OM, Mazoyer $S$, Puget $N$, Dubois $V$, Tonin $P$, Shugart $Y Y$, et al. Mutations in BRCA1 and BRCA2 in breast cancer families: are there more breast cancer-susceptibility genes? Am J Hum Genet. 1997;60(3):486-95.

24. Kwong A, Chen JW, Shin WY. A new paradigm of genetic testing for hereditary breast/ovarian cancers. Hong Kong Med J. 2016;22(2):171-7. https://doi.org/10.12809/hkmj154634.

25. Bracke X, Roberts J, McVeigh TP. A systematic review and meta-analysis of telephone vs in-person genetic counseling in BRCA1/BRCA2 genetic testing. J Genet Couns. 2021;30(2):563-73. Epub 2020 Nov 1. https://doi.org/10.1 002/jgc4.1343.

26. Ripperger T, Gadzicki D, Meindl A, Schlegelberger B. Breast cancer susceptibility: current knowledge and implications for genetic counselling. Eur J Hum Genet. 2009;17(6):722-31. https://doi.org/10.1038/ejhg.2008.212.

27. Chen S, Parmigiani G. Meta-analysis of BRCA1 and BRCA2 penetrance. J Clin Oncol. 2007;25(11):1329-33. https://doi.org/10.1200/JCO.2006.09.1066.

28. Sung PL, Wen KC, Chen YJ, Chao TC, Tsai YF, Tseng LM, et al. The frequency of cancer predisposition gene mutations in hereditary breast and ovarian cancer patients in Taiwan: from BRCA1/2 to multi-gene panels. PLoS One. 2017;12(9):e0185615. https://doi.org/10.1371/journal.pone.0185615.

29. Menko FH, Ter Stege JA, van der Kolk LE, Jeanson KN, Schats W, Moha DA, et al. The uptake of presymptomatic genetic testing in hereditary breastovarian cancer and Lynch syndrome: a systematic review of the literature and implications for clinical practice. Familial Cancer. 2019;18(1):127-35. https://doi.org/10.1007/s10689-018-0089-z.

30. Li X, Huang J, Zhang H. An analysis of hospital preparedness capacity for public health emergency in four regions of China: Beijing, Shandong, Guangxi, and Hainan. BMC Public Health. 2008;8(1):319. https://doi.org/10.11 86/1471-2458-8-319.

\section{Publisher's Note}

Springer Nature remains neutral with regard to jurisdictional claims in published maps and institutional affiliations. 